\author{
Military Technical \\ College \\ Kobry El-Kobba \\ Cairo, Egypt
}

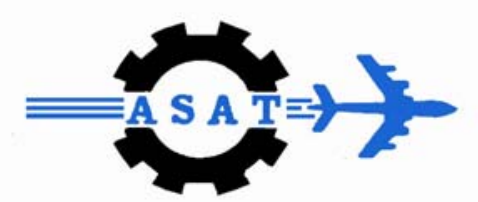

12-th International

Conference on

Aerospace Sciences \&

Aviation Technology

\title{
FLASH FLOODS SIMULATION USING SAINT VENANT EQUATIONS
}

\author{
Hossam Elhanafy *, Graham J.M. Copeland **.
}

\begin{abstract}
Flash floods prediction is considered one of the important environmental issues worldwide. In order to predict when and where the flood wave will invade and attack our lives, and provide solutions to deal with this problem it is essential to develop a reliable model that simulates accurately this physical phenomena. The research project reported in this paper is concerned with a study of unsteady free surface water flow, a hydrograph, resulting from a watershed just after the outlet station. To achieve this aim a numerical hydraulic model has been constructed to simulate the flow of water in the main stream based on the Saint Venant equations (SVE ${ }^{\mathrm{S}}$ ) using a staggered finite difference scheme to evaluate the discharge, the water stage, and the cross section area within the domain. While the Method Of Characteristics (MOC) is applied to achieve open boundary downstream and overcome the problem of reflections there. The developed model had passed a series of tests which indicated that this model is capable of simulating different cases of water flow that contain both steady and unsteady flow. Once the flood had been predicted it could be used as a stepping stone for different purposes including parameter identification (Ding et al. 2004), evaluating the sensitivity of the flood to some control variables (Copeland and Elhanafy 2006), Flood risk assessment (Elhanafy and Copeland 2007), uncertainty in the predicted flood (Elhanafy and Copeland 2007) and (Elhanafy et al. 2007).
\end{abstract}

\section{Keywords}

Flood risk assessment, Saint Venant equations, Watershed, Finite Difference Method, Method of Characteristics.

*PhD student, Civil Engineering Department, Strathclyde University, Scotland, U.K ${ }^{* *}$ Head of Civil Engineering Department, Strathclyde University, Scotland, U.K. 


\section{INTRODUCTION:}

\subsection{Floods forecasting}

Approaches to limit damage and disruption from flooding have changed significantly in recent years. Worldwide, there has been a significant move from a stratgy of flood defence to one of the flood risk mangement. Flood risk management includes the use of flood defences, where appropriate, but also recognises that more 'managed flooding' is essential to meeting goals for biodiversity and to sustain good ecological status in river and coastal systems. In future, society will come to appreciate and value the positive benefits of the river and coastal 'flood pulses', while simultaneously developing improved coping strategies that will make communities resilient to the negative impacts of flooding. However, the success of this approach depends on integrating: enhanced defences and warning systems with improved understanding of the river system and better governance, emergency planning and disaster management actions. The previous stratgy should be based over a reliable and accurate model that could be used to simulate the flood pulse spatially and temporarily.

That is why numerical techniques had been applied recently to hydraulic research and computional fluid dynamics for several purposes such as the prediction of circulation in estuaries for hazardous spill response (Cheng et al. 1993), the prediction of flood wave propagation in rivers (Steinebach 1998), coastal flow modelling (Copeland 1998), and evaluating the sensitivity of the flood to some control variables (Copeland and Elhanafy 2006). Once the outcome of an environmental hazard such as a flood wave propagation in our case has been predicted, it is important to consider what control actions will mitigate the impact of this hazards. Possible control actions in river flow systems that can be investigated using numerical models include the modification of reservoir release rates, the operation of control structures such as gates, locks, and weirs, the diversion of water into canals and floodplain storage facilities (Sanders and Katapodes 2000). Other 'controls' that act to determine the result of a model forecast, rather than offering an engineering control, are values of the inflow hydrograph and, for example, the values of other control variables such as bed friction, bed friction, infiltration rate, and channel topography. In this paper a hydrological model has been constructed based on Saint Venant equations which are solved using a staggered finite difference scheme while the up winding scheme is applied to overcome the stability problem of the convective term in the momentum equation.

Sanders and Katapodes (2000) documented that open boundary conditions at the hydraulic model must achieve dual objectives. First, the boundary conditions must supply to the model information from adjacent water bodies not included in the model. Second, the boundary conditions must allow disturbances generated within the solution domain to propagate without any changes through the computational open boundaries

In the case of stream flow we studied to achieve these objectives, the upstream driving hydrograph should be propagated through the domain without any disturbance till it reaches the downstream boundary and passes through it without any reflections. No physical mechanism is present in the real world to generate a reflection at computational open boundaries, so none should occur in the model. Otherwise, incorrect values of flood variables may be computed at the boundary, which can contaminate the information necessary to quantify boundary control. In this 
paper, we show the deriviation of characteristic equations for the flood wave propagation based on the main concept of the method of characteristics (MOC) for the shallow water equations by Abbott (1977).

Results at this paper are very encouraging and have demonstrated new ideas for addressing some issues in hydrologic modeling especially stream flow modelling and flood wave propagation.

\subsection{Mechanism of water flow:}

A watershed is composed of sub-areas and reaches (major flow paths in the watershed). Each sub-area has a hydrograph generated from the area based on the land and climate characteristics provided. Hydrographs from sub-areas and reaches are combined to accumulate flow as water moves from the upland areas down through the watershed reach network. The accumulation of all runoff from the watershed is represented at the watershed Outlet station (point B) at Fig. (1).
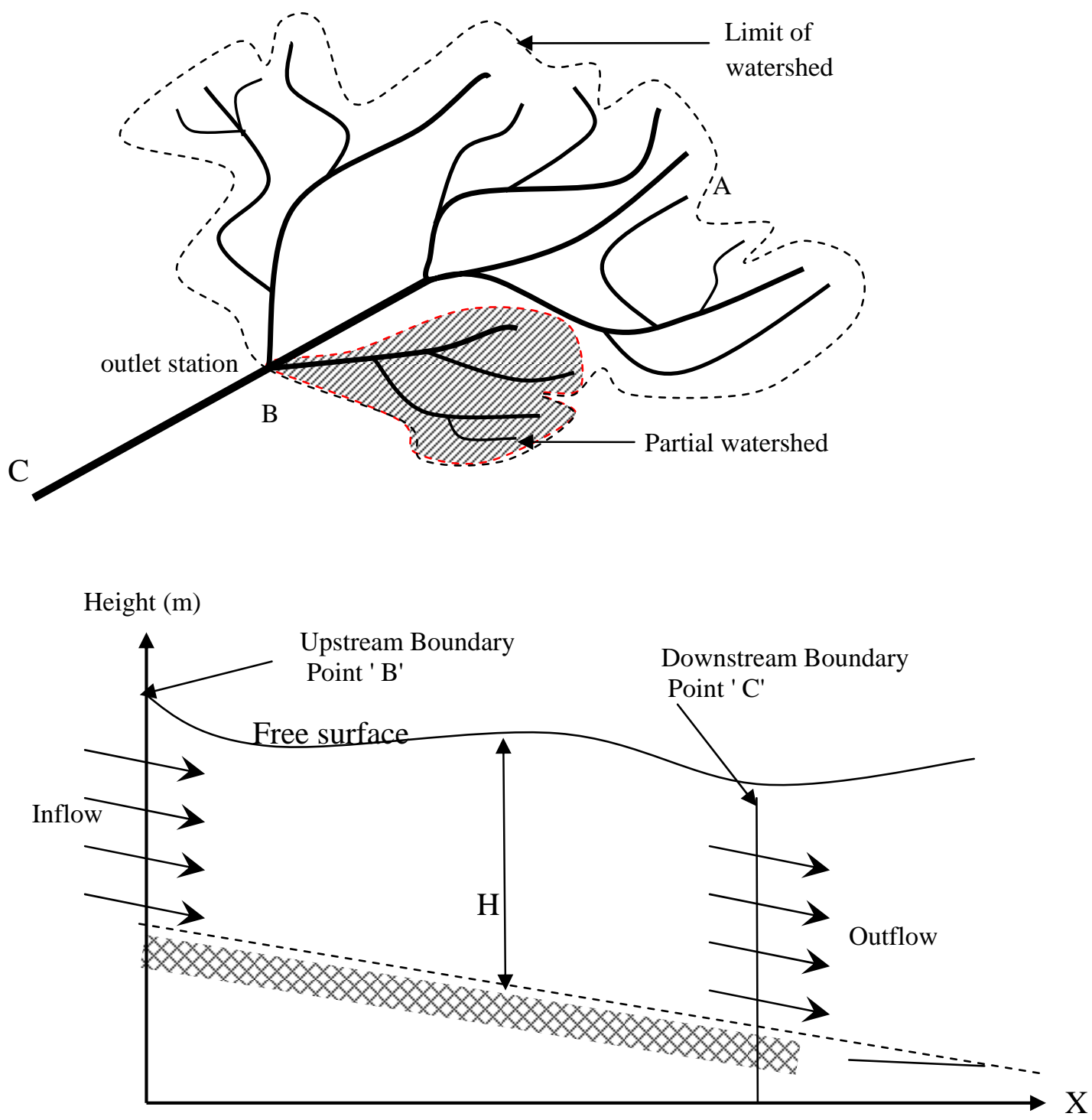

Fig.1. Flow within the Watershed 
So the hydrological response of a "watershed" could be divided into two different stages as illustrated in Fig. (1). each of them is completely different in its condition of water flow, behavior, parameters, and methods of study.

The first stage within a natural unit of land which is known as watershed in which water from direct precipitation, snowmelt, and other storage collects in a (usually surface) channel and flows downhill along the main stream from point "A" to point "B" which is the outlet station as illustrated in Fig.(1).

At the second stage the water flow is considered as channel flow from point "B" to point " $\mathrm{C}$ " which is completely different in its characteristics, the set of parameters that specifies the particular characteristics of the process, the mathematical relations describing its physical processes, physical meaning, and modeling.

A stream routing component is used to represent flood wave movement in a channel. The input for this component is an upstream hydrograph resulting from individual or combined contributions of sub area runoff, stream flow routings, or diversions. This hydrograph is routed to a downstream point, using the characteristics of the channel. The techniques available to route the runoff hydrograph include the Muskingum method, level-pool routing, and the kinematics wave method U.S. Army Corps of Engineer, (1988). All these techniques are base either on the Shallow Water Equations (SWE ${ }^{-}$) or on Saint Venant Equations (SVE $\stackrel{\text { S}}{\text { ). }}$.

\subsection{Flash floods and river floods:}

Flash floods are short-term rapid response inundations of small areas such as a town or parts of a city, usually by creeks and other smaller tributaries that flow into larger rivers. Heavy rain can produce flash flooding in a few hours even in places where little rain has fallen for weeks or months. In arid or semiarid regions, flash flooding can send a wall of water that turns a completely dry valley, wadi or canyon into a raging torrent in seconds.

If heavy rainfall occurs repeatedly over a wide area, then river or mainstream flooding becomes more likely, in which the main rivers of a region swell and inundate large areas, sometimes well after rainfall has ended as illustrated in Fig. 2. Groundwater and infiltration loss are important in this kind of flooding.

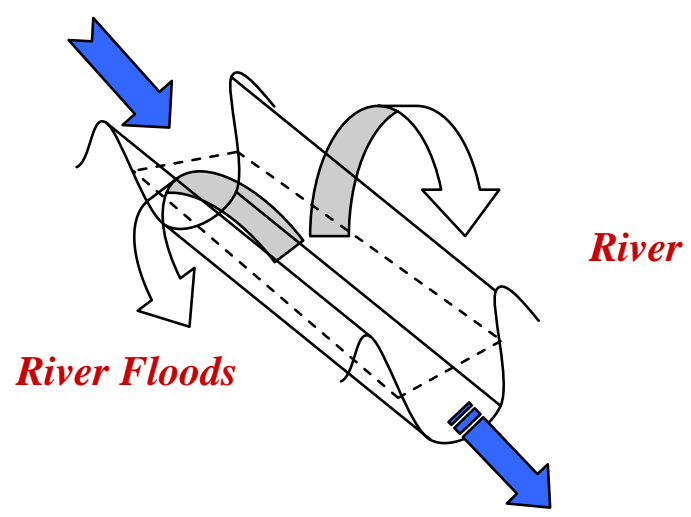

Flash floods

Fig.2. Flash Floods and River Floods 


\section{HYDROLOGICAL MODEL DEVELOPMENT}

A lot of numerical schemes (Nujic 1995; Jha et al. 1996; Jin and Fread 1997; Meselhe et al. 1997) has been developed to solve the open-channel flows with surges. However, most of these numerical models merely considered frictionless and horizontal channel flows. In this paper, a simple space and time staggered explicit finite difference scheme (Abbott et al 1989) had been developed to propagate and track the solution forward in time and space. The present model can calculate channel flows with bottom slope and friction terms in prismatic channel which are important controls for main stream routing. In addition, the method of characteristics is incorporated in the schemes to achieve open boundary conditions.

The method follows closely that described by Sanders and Katopodes (2000), Gejadze, I. Yu and Copeland, G.J.M., (2005).

The Nonlinear one dimensional Saint Venant Equations (SVE ${ }^{-}$) that form a system of partial differential equations which represents mass and momentum conservation along the channel and include source terms for the bed slope and bed friction may be written as:

$$
\begin{gathered}
\frac{\partial A}{\partial t}+\frac{\partial Q}{\partial x}=0 \\
\frac{\partial Q}{\partial t}+g A\left(\frac{\partial H}{\partial x}+\frac{\partial z}{\partial x}\right)+\frac{\partial(Q u)}{\partial x}+k \frac{Q|Q|}{A R}=0
\end{gathered}
$$

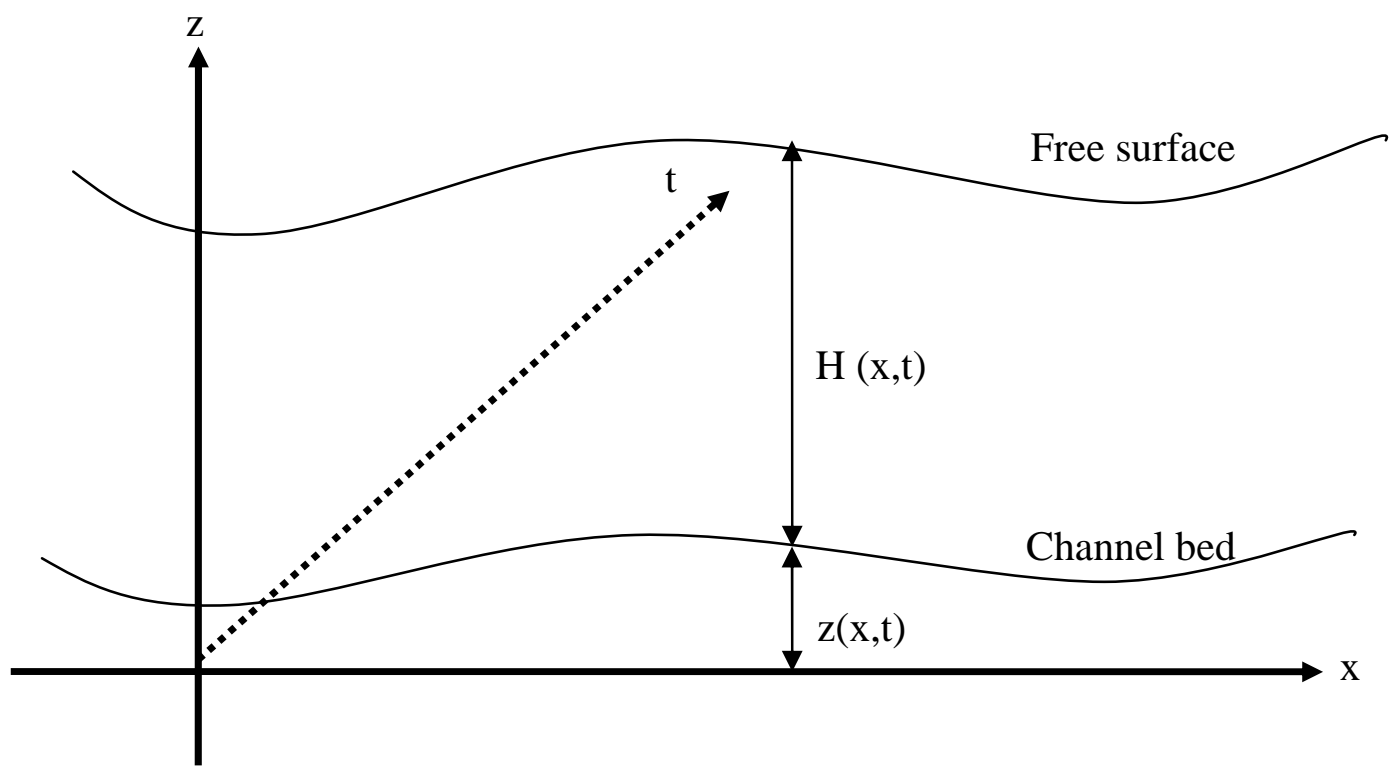

Fig.3. Flow in a channel with free surface under gravity.

where

$Q$ : $\quad$ is the discharge $\left(\mathrm{m}^{3} / \mathrm{s}\right)$.

$\mathrm{g}: \quad$ is the gravitational acceleration $\left(\mathrm{m} / \mathrm{s}^{2}\right)$. 
A : is the flow cross section area $\left(\mathrm{m}^{2}\right)$.

$\mathrm{H}: \quad$ is the total depth measured from the channel bed $(\mathrm{m})$.

$z$ : $\quad$ vertical distance between the datum and the channel bed as function $(x, t)$.

$\mathrm{t}: \quad$ is the time $(\mathrm{s})$.

$x$ : $\quad$ is the horizontal distance along the channel $(\mathrm{m})$.

$S_{0}: \quad$ is the bed slope $=-\frac{\partial z}{\partial x}$.

$\mathrm{K}: \quad$ is a friction factor $=\mathrm{g} / \mathrm{c}^{2}$ according to Chezy or $=\mathrm{gn}^{2} / \mathrm{R}^{(1 / 3)}$ according to Manning.

$\mathrm{R}: \quad$ is the wetted perimeter

\subsection{Introduction}

The main difference between CFD applications and other branches of computational physics is the importance of the convection term which is a first (odd) ordered spatial derivative (Leonard, 1983). And since the action of the convective term is to transport fluid properties from upstream boundary to downstream boundary, it is therefore necessary for the mathematical description to mirror these properties. Returning to the centered difference approximation with its inherently neutral sensitivity, the mathematical operation may be well dominated by fluctuations occurring either up or downstream. It is now clear that central differencing methods are inappropriate for modeling the convective terms [Couch, 2001].

\subsection{Higher-order finite difference techniques}

Since it is clear from the previous discussion that modeling the convective terms in the Saint Venant equations using central difference methods of any order is inappropriate. The alternative offered by first-order forward or backward differencing is unacceptable due to the poor numerical accuracy of such techniques. The only option available is to move to a higher-order scheme; upwind biased odd-ordered schemes of third-order and higher. The obvious effect of incorporating higher-order schemes is to increase both the numerical complexity and computational cost.

The finite-difference schemes based upon third-order upwinding have been found to offer good accuracy, inherent numerical stability and relative computational simplicity as cited in Couch [2001]. The success of third-order upwinding techniques has led to the proposal of numerous different schemes, such as QUICK [Falconer and Liu, 1988], QUICKEST, SHARP and SMART [Gaskell and Lau, 1988] all intended to improve a particular aspect or application of the basic third-order upwinding scheme. To model the effects of convective transport Fletcher [1991a, 1991b] algorithm had been applied to our research:

$$
\frac{\partial h}{\partial x}=\frac{h(x+\Delta x)-h(x-\Delta x)}{2 \Delta x}+\frac{\beta(h(x-2 \Delta x)-3 h(x-\Delta x)+3 h(x)-h(x+\Delta x))}{3 \Delta x}
$$

where $\quad \frac{\partial h}{\partial x}$ will be replaced by $\frac{\partial(Q u)}{\partial x}$. This equation contains two distinct parts, the first term in the (equation 3 ) is the simple centered difference. The second term provides a mechanism to modify the results obtained by selection of an appropriate value of the coefficient $\beta$. The advantage of using this particular 
algorithmic representation is the flexibility available to the user by varying the value of the coefficient $\beta$, the algorithm can be tuned to provide a second-order central difference scheme $(\beta=0)$, or coincide with Leonard's control-volume QUICK representation $(\beta=0.375)$, or a fully third-order upwind scheme $(\beta=0.5)$. Further increasing the value of the coefficient $\beta$ above 0.5 produces a smoother but more diffuse solution as the weighting of the upwind biased term is increased, eventually producing a solution more similar to that of a simple two-point upwind scheme.

\subsection{Boundary conditions:}

Flooding is created at the upstream boundary by defining a three hours hydrograph as presented in fig. 4 .

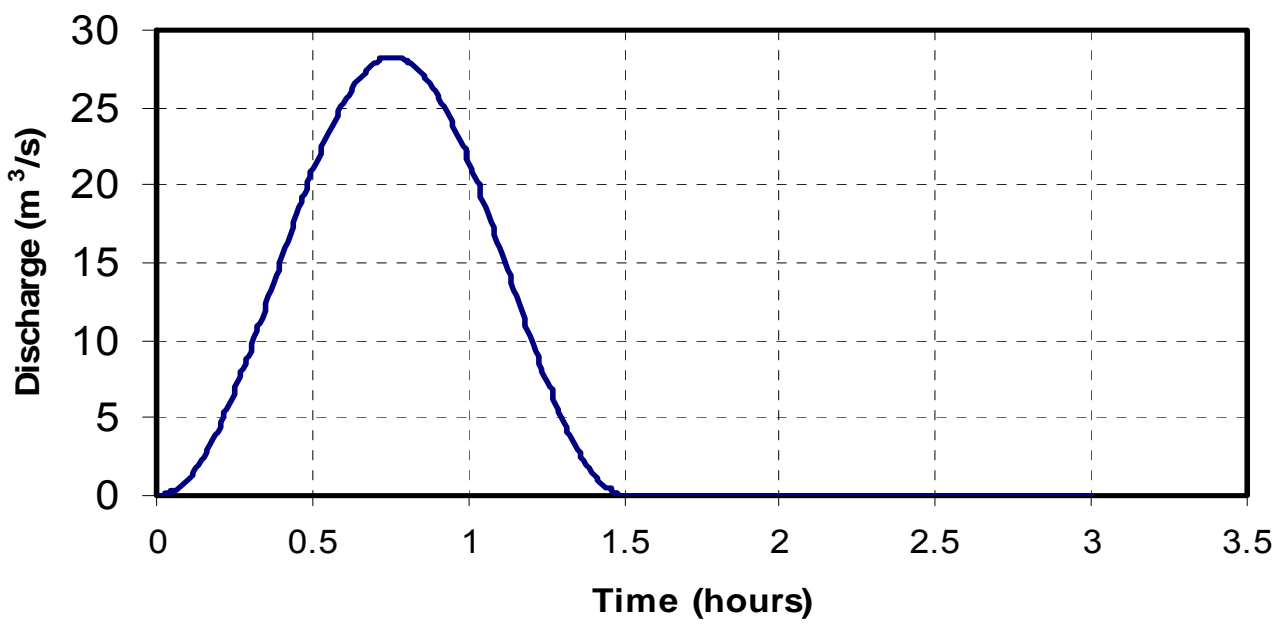

Fig.4. A three hours hydrograph at the upstream boundary

While the downstream boundary is set to be open boundary which is achieved by the application of the Method of Characteristics (MOC) (Abbott 1977) and following a standard text such as (French, 1986) that had been derived for the characteristics of the linearized SWE $\underline{\underline{s}}$, the characteristics of the 1-D SVE $\underline{\underline{S}}$ had been derived by the authors and the final formula is identified as:

$\Delta Q+(c-u) \Delta A+k \frac{q|q|}{A R}+g A \frac{\partial z}{\partial x}=0$ along $\mathrm{dx}=\mathrm{cdt}$ (the positive characteristic)

$\Delta Q-(c-u) \Delta A+k \frac{q|q|}{A R}+g A \frac{\partial z}{\partial x}=0 \quad$ along $\mathrm{dx}=\mathrm{cdt}$ (the negative characteristic)

where $(\Delta)$ indicates a total change in variable along the characteristic path.

These are used in the discrete equations to find the boundary values $Q(0, t)$ and $A(s, t)$ as follow:

From equation [4]

$$
\frac{\Delta Q}{\Delta t}+(c-u) \frac{\Delta A}{\Delta t}=-k \frac{q|q|}{A R}-g A \frac{\partial z}{\partial x}
$$

So

$$
(c-u) \frac{\Delta A}{\Delta t}=-\frac{\Delta Q}{\Delta t}-k \frac{q|q|}{A R}-g A \frac{\partial z}{\partial x}
$$


Divide both sides by c $\quad \frac{\Delta A}{\Delta t}=\left(-\frac{\Delta Q}{\Delta t}-k \frac{q|q|}{A R}-g A \frac{\partial z}{\partial x}\right) /(c-u)$

Multiply both sides by $\Delta t$

$$
\Delta A=\left(-\frac{\Delta Q}{\Delta t}-k \frac{q|q|}{A R}-g A \frac{\partial z}{\partial x}\right) * \frac{\Delta t}{(c-u)}
$$

From equation [6] we could get the boundary value of $A$ at the downstream boundary and consequently we could get the value of the water stage $(\mathrm{H})$, top water width.

\subsection{Discretization of the developed model}

The numerical scheme follows a simple space and time staggered explicit finite difference scheme as illustrated in (fig. 5).

The discharge $(Q)$ is marched using the discrete form of the momentum equation:

$Q(i, j+1)=Q(i, j)-(\Delta t / \Delta x) g A(i, j)[A(i, j)-A(i-1, j)]-(\Delta t)[K Q(i, j)|Q(i, j)| / A(i, j) R(i, j)] \quad$ [eq.7] The cross section area $(A)$ is marched using the discrete form of the continuity equation:

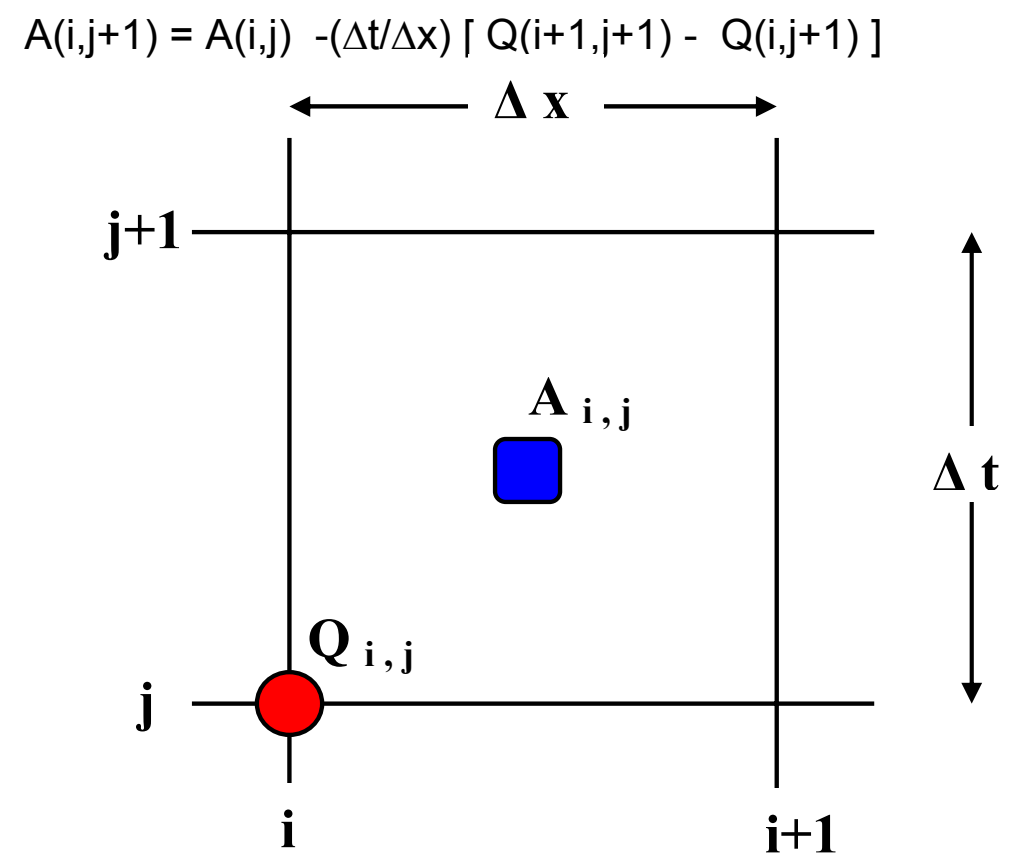

Fig.5. The discretization scheme

\subsection{Stability of the scheme}

It is essential that the finite difference scheme used should be fully tested for stability before proceeding with developing the numerical model. To investigate analytically the stability of the staggered explicit finite difference scheme that present Saint Venant equations [1,2] the Fourier method had been applied and as a result this scheme will be stable if and only if $C F L \leq 1.0$, where: 
$C F L=\frac{\Delta t}{\Delta x} \sqrt{\frac{g A}{T}}$, is the Courant-Friedrich-Lewy number, and $\mathrm{T}$ is the channel top width. So a value of $C F L=0.5$ was used in the test cases described below

\section{MODEL VERIFICATION}

Developing a complete test to check and validate an exact solution for the nonlinear Saint Venant Equations (SVE ${ }^{\text {) }}$ ) is not possible. It is possible however to develop simple tests to compare the model results with analytical solutions of certain idealized cases. Several tests have been carried out to verify the model from uniform steady flow to non-uniform unsteady flow; we will mention here just the two most important tests.

\subsection{Validation test 1 - non-uniform unsteady flow}

The main objectives of this test are to assure that the value of both the discharge (Q) and the water depth $(\mathrm{H})$ at the upstream propagate downstream without any change and the relationship between $Q$ and $H$ follow the analytical solution of the shallow water wave. The results of the model are a driving upstream boundary hydrograph of peak discharge $Q=28.24 \mathrm{~m}^{3} / \mathrm{s}$ and the calculated upstream boundary hydrograph of peak value, $\mathrm{H}_{\max }=21.96 \mathrm{~m}$. while the wave speed is $14.74 \mathrm{~m} / \mathrm{s}$.

So, the first conclusion is that the relationship calculated by the model typically follow the shallow water wave, the second conclusion is that the hydrograph traveled from the upstream boundary to the down stream boundary with a small change in the peak discharge from $28.01 \mathrm{~m}^{3} / \mathrm{s}$ to $28.24 \mathrm{~m}^{3} / \mathrm{s}$ and from $21.96 \mathrm{~m}$ to $21.94 \mathrm{~m}$ for the peak water depth as illustrated at Figure (6) and this acceptable diffusion is duo to the numerical dissipation of the used explicit scheme. The last conclusion is that the wave traveled a distance of $151.26 \mathrm{Km}$. within $10260 \mathrm{sec}$. so its speed is $14.74 \mathrm{~m} / \mathrm{s}$. while the speed of the wave should equal to $\sqrt{\frac{g A}{T}}=14.69 \mathrm{~m} / \mathrm{s}$ which is nearly the same. So finally, it is clear there is a good agreement between the analytical solution and the developed model and also there is no numerical dissipation.

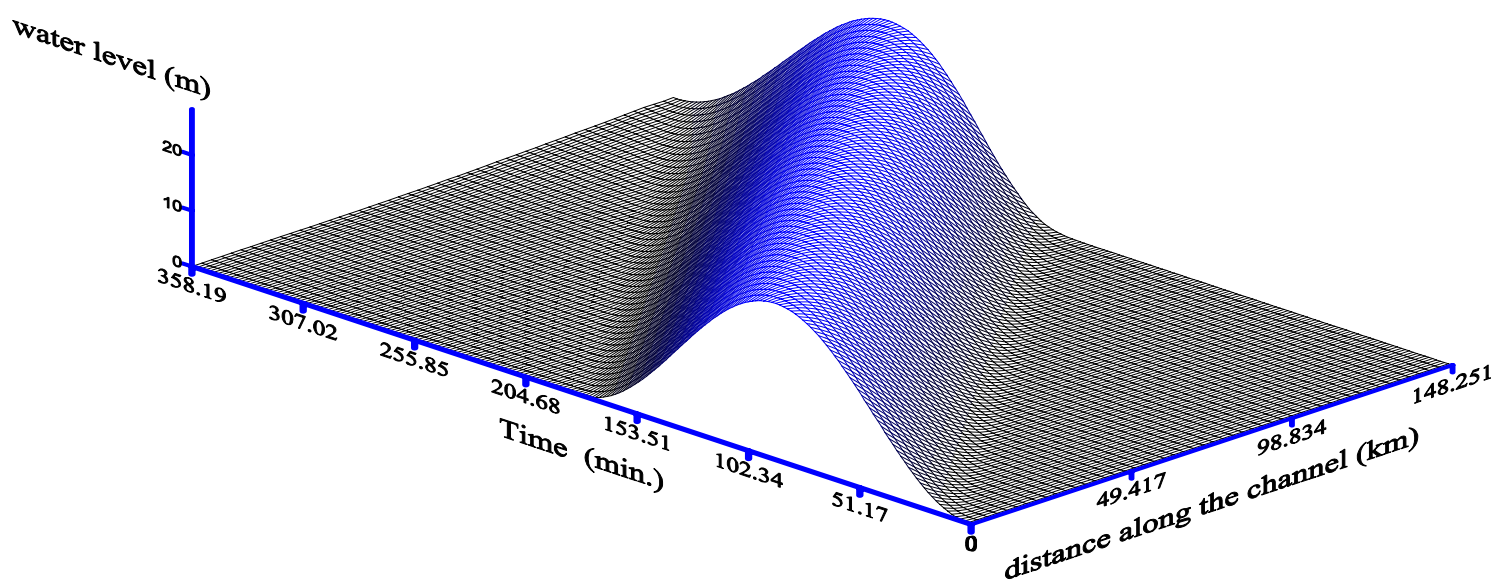

Figure (6). Water depth $(\mathrm{H})$ within the domain 


\subsection{Validation test 2 - Unsteady flow within a sloping channel and rough bed}

The objective of this test is simply to look for the whole channel as a control volume to assure there is no significant losses or accumulation in volume within the simulated domain and the results of this tests are not compared with the analytical solution only, but are compared with other model results as well. If we considered the initial water depth is $\mathrm{H}_{\mathrm{i}}$ and at the end of the simulation is $\mathrm{H}_{\mathrm{f}}$. While the driving discharge upstream is $q_{u}$ and downstream is $q_{d}$ so, we could say the total volume enters the channel is $\Delta V_{1}=\int Q_{u} d t-\int Q_{d} d t$, while the total volume leaves the channel is $\Delta V_{2}=\int A_{f} d x-\int A_{i} d x$, to be in equilibrium, it should be $\Delta V_{1}=\Delta V_{2}$. The model was applied for non-uniform unsteady flow conditions within a slopping channel and rough bed. The initial water depth was chosen $\mathrm{H}_{\text {initial }}=20.0 \mathrm{~m}$. The result of the flood wave propagation within the domain is presented at Figure (7). $\Delta V_{1}=5284.95 \mathrm{~m}^{3}$ and $\Delta V_{2}=5330.36 \mathrm{~m}^{3}$ So, $\Delta V_{2}-\Delta V_{1} \cong 45.41 \mathrm{~m}^{3} \approx 0.86 \%$ which is acceptable and it is very small error compared to several previously developed model such as Abiola and Nikaloaos (1988) which was overestimated by $28 \%$.

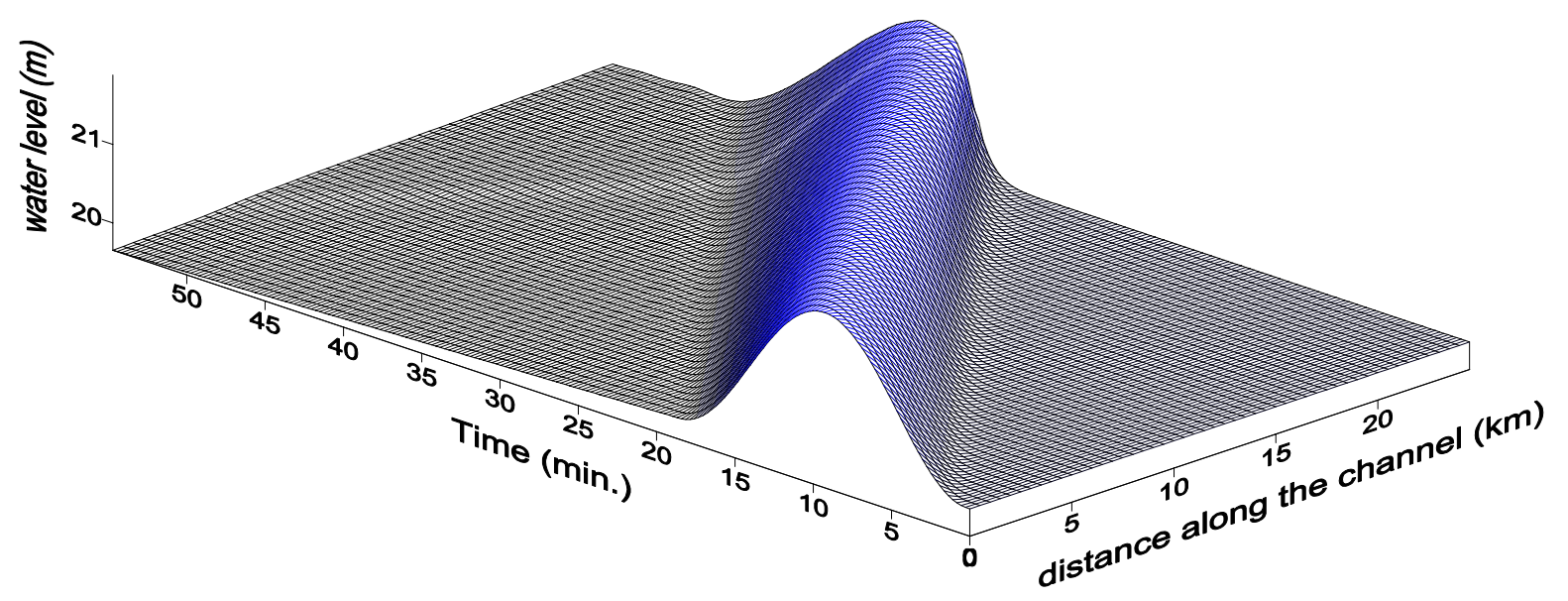

Figure (7) Water depth $(\mathrm{H})$ within the domain

\section{CASE STUDY}

\subsection{Case (1)}

\subsubsection{Description}

A $1.0 \mathrm{~m}$ width rectangular horizontal channel (fig. 9) with a driving upstream hydrograph (producing wave of initial amplitude $2.0 \mathrm{~m}$ ) in uniform water depth without bed friction.

A hydrograph was defined that produce a wave of initial amplitude $a=2.0 \mathrm{~m}$ with maximum discharge of $29.5 \mathrm{~m}^{3}$ in a $20 \mathrm{~m}$ water depth. The grid was $\mathrm{nt}=400$ time steps and $n x=50$ space steps that result in a domain size of length $L=75.0 \mathrm{Km}$ and time $t=5.6$ hours, the upstream driving boundary is a three hours hydrograph of 29.5 $\mathrm{m}^{3}$ max. discharge fig. (4). the wave speed $\mathrm{c}=\sqrt{\frac{g A}{T}}$ everywhere.

This gave values $d x=1.5 \mathrm{Km}$ and $d t=50$ seconds. The initial condition was $H(x, 0)=$ $20 \mathrm{~m}$ and $\mathrm{Q}(\mathrm{x}, 0)=0$ 


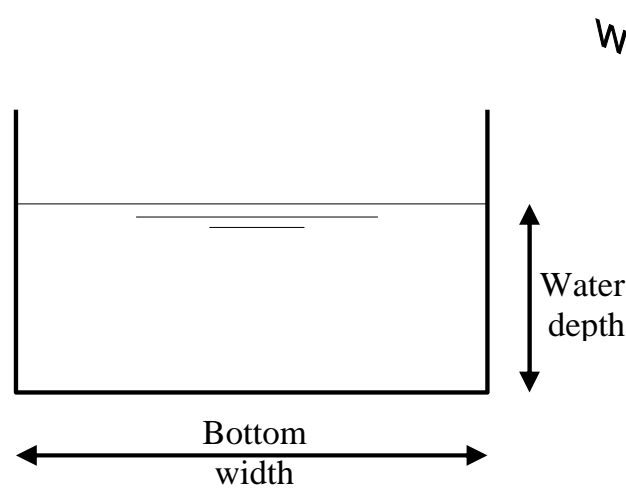

Figure (8) Channel cross section

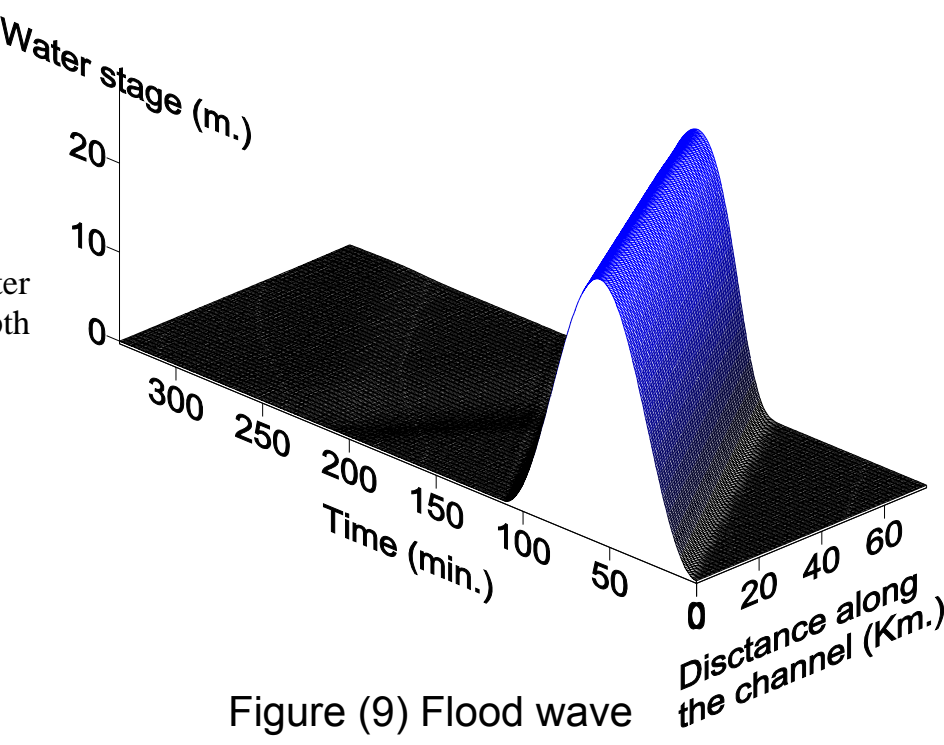

\subsubsection{Results and Result Analysis for case (1)}

The hydrograph traveled from the upstream boundary to the downstream boundary without any decreasing in the maximum discharge as shown in (fig. 9) because the channel is horizontal and no bed friction term at the momentum equation. And since there is no change in the cross section properties the water stage did not change along the characteristic line.

\subsection{Case (2):}

\subsubsection{Description:}

A trapezoidal horizontal channel (fig. 11) with a $2.0 \mathrm{~m}^{3} / \mathrm{s}$. constant discharge upstream in uniform water depth without bed friction.

A $30 \mathrm{Km}$. channel is studied for one hour period. The cross section of the channel is chosen to be trapezoidal section as illustrated at fig. (10) with $10.0 \mathrm{~m}$. bottom width. While a contraction of $0.25 \mathrm{~m}$. is created gradually at the middle of the channel as illustrated in the plan view fig (11). The grid was $\mathrm{nt}=180$ time steps and $\mathrm{nx}=50$ space steps. The upstream boundary is a steady discharge of $2.0 \mathrm{~m}^{3} / \mathrm{s}$. The initial condition was $H(x, 0)=20 \mathrm{~m}$ and $Q(x, 0)=2.0 \mathrm{~m}^{3} / \mathrm{s}$.

\subsubsection{Results and Result Analysis for case (2):}

As shown in fig (12) a reduction of $0.25 \mathrm{~m}$ in the channel width generate a sudden change in the water level from $20.0 \mathrm{~m}$. to $20.5 \mathrm{~m}$. and the same result could be obtained if a sudden change happened to the bed level. In other words, any change in the flow cross section will definitely affect the water level and this coincides with the basic principals of hydraulics, momentum conservation. This simple illustration should be taken into consideration while constructing any detention dams along the flood streams especially if they are executed by non specialized person, because if the channel cross section can not afford the this sudden change in the water level the 
result will be not a flood in the main stream only but an inundation would be expected (fig. 2).

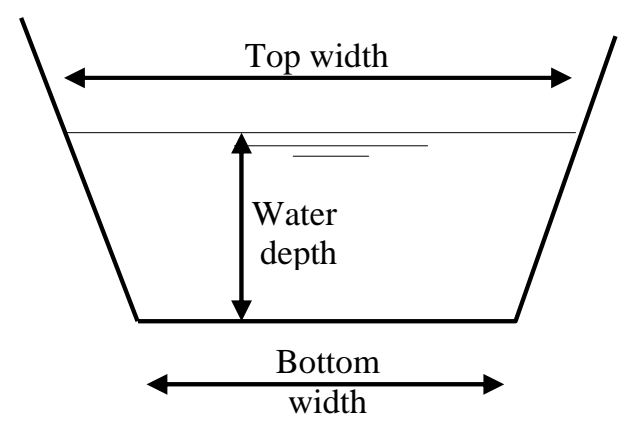

Figure (10) Channel cross section

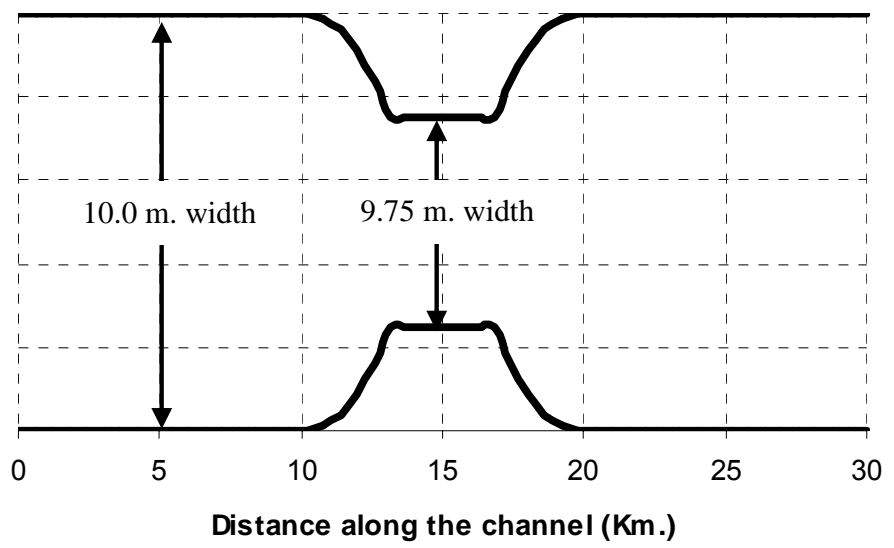

Figure (11) Plan view of the studied channel

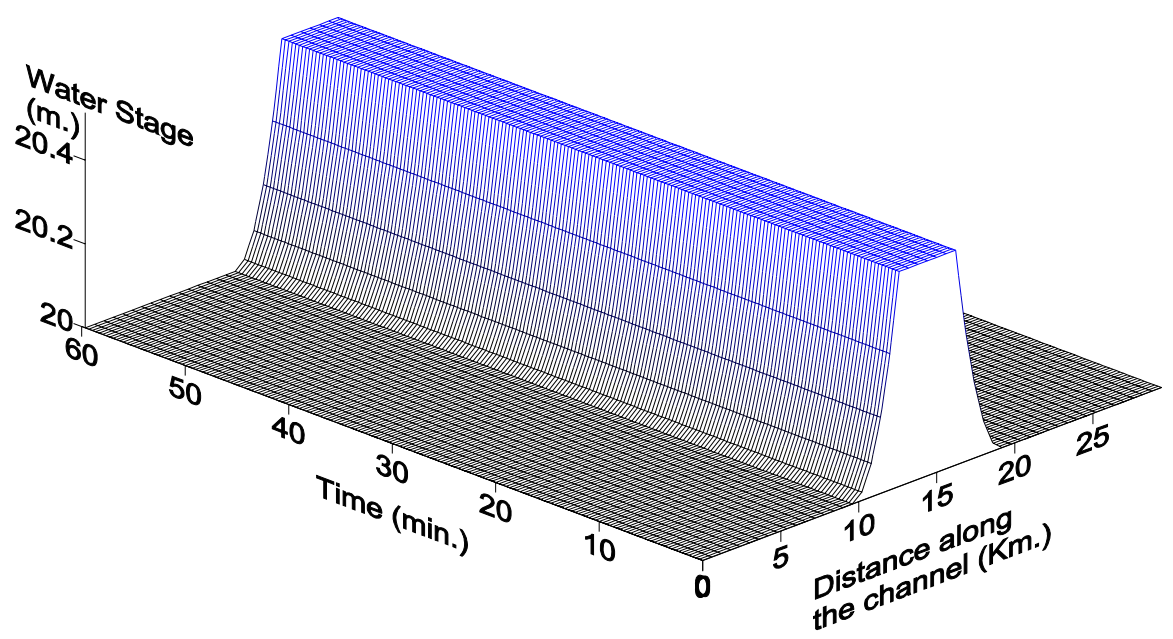

Fig.12. The water stage along the channel

\section{CONCLUSIONS}

This approach had be used by the authors as a stepping stone to both the sensitivity analysis and uncertainty analysis i.e. looking at effects of uncertainties in combinations of parameters on the predicted flood level along the channel but without taking the effect of the channel cross section, i.e. the flood wave had been studied using a one dimensional Shallow water equation (Copeland and Elhanafy 2006). And since it had been improved now by taking the channel geometry and the model proved its capability of simulating both steady and unsteady flow efficiently, a research will be continuo by studying more complicated channel geometry and may focus on the predicted uncertainties. 
In this paper a staggered numerical schemes for simulating 1D, steady and unsteady open-channel flows based on the Saint Venant Equation (SVE- ) had been used while the method of characteristics had been used to achieve transparent boundary downstream. Furthermore, results of the proposed schemes exhibit high accuracy and robust stability for channel flows with non linear terms. In addition, the results indicated that the steady routing may underestimate the water depth during the flood period. Therefore, steady routing may result in unsafe designs for protection structures against flash floods and for stream planning.

Also this study should be announced to the community in the areas which are expected to suffer from floods in a simple instructions and flood policy in order to increase the knowledge to some people who live in flood plains about how so dangers to do any changes to the channel sections without referring to the authorized authorities.

\section{ACKNOWLEDGMENTS}

Many helpful discussions about the uncertainties with $\mathrm{Dr}$ Igor $\mathrm{Yu}$ Gejadze, Strathclyde University are gratefully appreciated.

\section{REFERENCES}

1 Abbott, M.B. and Basco, D.R. (1989) 'Computational Fluid Dynamics: An Introduction for Engineers', Longman Scientific \& Technical, Essex, UK.

2 Abbott, M.B., (1977) 'An Introduction to the method of characteristics', Thames and Hudson, London, UK.

3 Abiola, A.A. and Nikaloaos, D.K. (1988). "Model for Flood Propagation on Initially Dry Land". ASCE Journal of Hydraulic Engineering, vol 114, No. 7

4 Cheng, R. T., Casulli, V., and Gartner, J. W. (1993). "Tidal, residual, intertidal mudflat (TRIM) model and its application to San Francisco Bay, California." Estuarine, Coast. and Shelf Sci., 36, 235-280.

5 Copeland, G.J.M. (1998), Coastal Flow modeling using an inverse method with direct minimization, Proc. Conf. Estuarine and Coastal Modeling, 1997. Ed. M. L. Spaulding \& A.F. Blumberg, Pub. ASCE (ISBN 0-7844-0350-3) pp.279-292.

6 Copeland, G.J.M. and El-Hanafy, H., (2006). ' Computer modelling of channel flow using an inverse method', Proc. 6th Int. Conf. on Civil and Arch. Eng, Military Technical College, Kobry Elkobbah, Cairo Egypt.

7 Couch S.J., (2001) 'Numerical modelling of tidal flow around headlands and islands' PhD thesis, university of Strathclyde, Scotland, U.K.

8 El-Hanafy, H. and Copeland, G.J.M., (2007). 'Flood risk assessment using adjoint sensitivity analysis', Proceedings of 32nd IAHR Congress, The International Association of Hydraulic Engineering and Research, Venice, Italy.

9 El-Hanafy, H. and Copeland, G.J.M., (2007). 'modelling uncertainty for flash floods in coastal plains adjoint method', Proc. of Second international conference and exhibition on water resources, technologies and services, Sofia, Bulgaria

10 El-Hanafy, H., Copeland, G.J.M., and Gejadze I.Y., (2007). 'Estimation of predictive uncertainties in flood wave propagation in a river channel using adjoint sensitivity analysis', Proc. of the ninth international conference on Computational Fluid Dynamics (CFD), Institute for Computational Fluids 
Dynamics (ICFD), London., U.K.

11 Falconer, R.A. and Liu, S.Q. (1988). 'Modelling Solute Transport Using QUICK Scheme'. ASCE Journal of Environmental Engineering, 114, pp. 3-20.

12 Fletcher, C.J. (1991a). 'Computational Techniques for Fluid Dynamics 1: Fundamental and General Techniques', Springer-Verlang.

13 Fletcher, C.J. (1991b). 'Computational Techniques for Fluid Dynamics 2: Specific Techniques for Different Flow Categories'. Springer-Verlang.

14 French, R.H. (1986), 'Open Channel Hydraulics', McGraw Hill

15 Gaskell, P.H. and Lau, A.K.C. (1988). 'Curvature-Compensated Convective Transport: SMART, a new Boundness-Preserving Transport Algorithm'. International Journal for Numerical Methods in Fluids, 8, pp. 617-641.

16 Gejadze, I. Yu and Copeland, G.J.M., (2005) 'Open Boundary Control for Navier-Stokes Equations Including the free Surface: Adjoint Sensitivity Analysis', Computers \& Mathematics with Applications, Elsevier.(accepted for publication)

17 Jha, A. K., Akiyama, J., and Ura, M. (1996). 'A fully conservative Beam and Warming scheme for transient open channel flows.' J. Hydr. Res., Delft, The Netherlands, 34(5), 605-621.

18 Jin, M., and Fread, D. L. (1997). 'Dynamic flood routing with explicit and implicit numerical solution schemes.' J. Hydr. Eng., ASCE, 123(3), 166-173.

19 Leonard, B.P. (1981). 'A Survey of Finite Differences With Upwinding for Numerical Modelling of the Incompressible Convective Diffusion Equation'. Computational Techniques in Transient and Turbulent Flow. Vol. 2 in series. Recent Advances in Numerical Methods in Fluids, Edited by Taylor, C. and Morgan, K. Pp.1-35., Pineridge Press Ltd.

20 Leonard, B.P. (1983). 'Third-Order Upwinding as a Rational Basis for Computational Fluid Dynamics'. Computational Techniques \& Applications: CTAC-83, Edited by Noye, J. And Fletcher, C., Elsevier.

21 Meselhe, E. A., Sotiropoulos, F., and Holly, F. M., Jr. (1997). 'Numerical simulation of transcritical flow in open channels.' J. Hydr. Eng., ASCE, 123(9), 774-783.

22 Nujic, M. (1995). 'Efficient implementation of non-oscillatory schemes for the computation of free-surface flows.' J. Hydr. Res., Delft, The Netherlands, 33(1), 101-111.

23 Sanders, B.F and Katopodes, N.D. (2000) 'Adjoint Sensitivity analysis for shallow-water wave control'. J. Eng. Mech., ASCE, pp 909-919

24 Steinebach, G. (1998). 'Using hydrodynamic models in forecast systems for large rivers', Advances in hydro science and engineering, K. P. Holz, W. Bechteler, S. S. Y. Wang, and M. Kawahara, eds., Vol. 3.

25 U.S. Army Corps of Engineer, (1988), 'HEC-1, flood hydrology Package' (1988 version): Hydrologic Engineering Centre, Davis, California. 